\title{
PERSPECTIVES OF THE INHALED ANTIBIOTICS USAGE IN PEDIATRICS
}

\author{
Oksana BOYARCHUK ${ }^{1}$, Halyna KRYTSKA ${ }^{2}$, Andrii CHORNOMYDZ ${ }^{3 凶}$, Volodymyr PELYKH ${ }^{4}$, \\ Iryna CHORNOMYDZ ${ }^{1}$, Tetiana KOSOVSKA ${ }^{1}$, Ihor HORISHNYI ${ }^{1}$
}

${ }^{1}$ Department of Children Diseases and Pediatric Surgery, I. Horbachevsky Ternopil State Medical University, Ternopil, Ukraine

${ }^{2}$ Department of General Hygiene and Ecology, I. Horbachevsky Ternopil State Medical University, Ternopil, Ukraine

${ }^{3}$ Department of Pharmacology and Clinical Pharmacology, I. Horbachevsky Ternopil State Medical University, Ternopil, Ukraine

${ }^{4}$ Department of Pathophysiology, I. Horbachevsky Ternopil State Medical University, Ternopil, Ukraine

Received 15 Feb 2018, Accepted 02 May 2018

\section{Abstract}

The antibacterial therapy in children remains a complicated and an unsolved problem of medicine. Despite the fact that antibiotics are largely available, every year more and more bacteria become resistant to these drugs. Also, there is only a small number of new antibacterial agents introduced into practice, especially for respiratory system infections. This is due to the fact that systemic antibiotics poorly penetrate into the pulmonary tissue and do not create high concentrations at the site of inflammation. With increased doses of systemic antibacterial agents, their toxic effect on the body of the patient also increases. Therefore, the usage of inhalation route for the intake of these agents is a modern one and reduces the risk of systemic side effects. In the literature review conducted by us, the main advantages of inhalation intake of antibiotics have been examined, the analysis of the basic preparations usage has been carried out and the disadvantages and side effects of the inhalation route of the antibacterial agents intake have been identified. It is also worth

\section{Résumé}

Perspectives d'utilisation des antibiotiques inhalés en pédiatrie

La thérapie antibactérienne chez les enfants reste un problème complexe et non résolu de la médecine. Malgré le fait que les antibiotiques forment l'un des groupes de remèdes le plus répandu, chaque année de plus en plus de bactéries deviennent résistantes à ces médicaments. Un petit nombre de nouveaux antibactériens introduits en pratique reste également un moment négatif. Ce problème devient particulièrement actuel lors de maladies respiratoires. Cela est due au fait que les antibiotiques systémiques pénètrent assez mal dans le tissu pulmonaire et ne créent pas de hautes concentrations au site de l'inflammation. Avec l'accroissement du nombre de dosages des antibactériens systémiques augmentent aussi leurs effets toxiques sur l'organisme du patient. Par conséquent, l'utilisation de ces médicaments par voie inhalée est de perspective et réduit le risque de développement 
noting that the inhaled antibiotics are practically not used as monotherapy, but only in combination with antibiotics with systemic action. They cannot be an alternative or a substitute for systemic drugs. The usage of this group of drugs makes it possible to improve the results of treatment of the respiratory diseases in children, especially with chronic inflammatory processes. The inhaled antibiotics can be one more important step in the fight against antibiotic resistance.

Keywords: antibacterial agents, inhaled antibiotics, inflammatory respiratory diseases, children, nebulizer therapy. d'effets secondaires systémiques. Suite à notre revue de la littérature nous avons examiné les avantages principaux des antibiotiques par voie inhalée, nous avons analysé l'utilisation de médicaments essentiels et nous avons déterminé les inconvénients et les effets secondaires de la voie inhalée des antibactériens. Il mérite également à noter que les antibiotiques inhalés ne sont pratiquement pas utilisés en monothérapie, mais seulement en association avec des antibiotiques systémiques. Ils ne peuvent pas être une alternative ou un substitut aux médicaments systémiques. L'utilisation de cette classe de médicaments permet d'améliorer les résultats du traitement des maladies respiratoires chez les enfants, tout particulièrement dans l'inflammation chronique. Les antibiotiques inhalés peuvent devenir une autre étape importante dans la lutte contre la résistance aux antibiotiques.

Mots-clés: antibactériens, antibiotiques inhalés, maladies inflammatoires des poumons chez les enfants, thérapie par nébulisation.

Delivery of antibiotics through inhalations has significant benefits in the treatment of lower respiratory tract infections, compared with systemic (oral or intravenous) therapy. Among the main undoubted advantages of using IA are:

- Direct delivery of the antibiotic to the infection site. Usage of modern nebulizers allows to deliver $50-70 \%$ of the IA dose actually into the center of infection ${ }^{1,9}$;

- Achieving high concentrations of antibiotic in the sputum, which is significantly higher than after intravenous intake, that is especially important in the treatment of infections caused by polyresistant strains and preventing the appearance of resistance $^{1,10,11}$;

- Reducing the risk of systemic toxic effect of antibiotics, due to the minimal systemic absorption of drugs ${ }^{1,9,12}$

- Possibility of usage in patients of any age ${ }^{6}$;

- Aerosol intake of high concentrations of antibiotics (in particular, aminoglycosides) allows overcoming the antagonistic effect of the purulent sputum on the biological activity of the drug ${ }^{13}$;

- Reduced number of hospitalizations;

- Positive effect on the quality of the patients' life;

- Possibility of therapy at home ${ }^{12,13}$.

Using modern nebulizers, the drug can be inhaled when the patient breathes in a relaxed state. So, no specific inhalation maneuver is required ${ }^{6}$.

The effectiveness of the inhalation drug is also determined by many factors that influence the distribution of the drug in the respiratory tract (type of 
nebulizer and compressor, size of the particles of the drug, rate of the aerosol delivery, age of the patient, severity of the underlying disease) ${ }^{14}$.

It is important to note that the inhaled antibiotics are not used as a monotherapy without systemic drugs, because their degree of absorption into the blood is low (2-4\%) and not sufficient for systemic effect and treatment of concomitant infections and secondary lesions ${ }^{8}$.

Indications for the inhaled antibiotics usage for treating respiratory tract infections in children have not been defined until today. Further studies are needed to determine the significance of these drugs in infancy patients.

The largest domestic and foreign experience of using IA is accumulated in the treatment of acute and chronic infection in patients with cystic fibrosis, with exacerbation of bronchiectasis and severe pneumonias. In particular, the aerosolized antibiotics reduce the frequency of exacerbations, reduce the density of sputum in the respiratory tract, improve the function of the lungs, improve the quality of life in patients with cystic fibrosis ${ }^{15}$. Therefore, these dosage forms are considered to be standard for a long-term treatment of lung deficiency with cystic fibrosis and are recommended by the American Thoracic Society (ATS) in the Clinical Pulmonary Guidelines ${ }^{15,16}$.

According to a large German study conducted by S. Ehrmann et al. ${ }^{17}, 99 \%$ of physicians from resuscitation departments use an inhalation method of drugs intake, among them $43 \%$ use nebulizers (55\% jet, $44 \%$ ultrasound, $14 \%$ nebulizers with a vibrating plate). $80 \%$ of the respondents use inhaled colistin, and $30 \%$ conduct inhaled antibiotic therapy at least once every 2 months $s^{1,17}$.

Unfortunately, today, a small amount of antibiotics can be used by inhaling, and solutions for parenteral use have high osmolarity, acidity and contain preservatives, in particular phenols, that irritate the respiratory tract (cough, wheezing, chest pain) ${ }^{10}$. At present, special inhalation forms for the patients treatment exist only for colistin, tobramycin and aztreonam ${ }^{10,18}$. Also, in recent years, the inhaled fluoroquinolones, amikacin, cephalosporins, phosphomycin, vancomycin and others began to be used in some countries. Perspective is the usage of the inhaled antibiotics combinations: phosphomycin/tobramycin, colistin/tobramycin ${ }^{8}$.

\section{Colistin}

The antibiotic colistin (colistimethate sodium) belongs to the group of polymyxins. It was first detected in the middle of the $20^{\text {th }}$ century, as a product of the bacteria Bacillus colistinus fermentation ${ }^{15}$. Due to their cationic nature, polymyxin antibiotics are capable of damaging cell membranes of bacteria ${ }^{14}$. Colistin is a bactericidal antibiotic and active against Gram-negative bacteria, including P. aeruginos ${ }^{15}$. Colistin is included into the clinical practice for the treatment of carbapenem resistant gram-negative bacteria. The inhaled colistin $(50-75 \mathrm{mg}, 2-3$ times a day) is used for the long-term treatment of the cystic fibrosis infectious complications, both in hospital and in outpatients. In addition, colistin is used for the treatment of ventilated and associated pneumonias and severe infectious diseases of lungs caused by the Gram-negative flora, especially the Pseudomonas aeruginosa ${ }^{1}$.

There are no specific requirements for inhalation devices of colistimethate sodium, so the drug can be intaken with ultrasonic or jet nebulizers or devices with a pulse flap (mesh devices) ${ }^{14}$.

In 2011 a randomized, double-blind, phase III study on safety of a new form of colistimethate sodium in the form of powder that was used through the inhaler (Colobreathe, Forest Laboratories, UK) was completed and, after the drug registration by the European Medicines Agency in 2012, it began to be applied in Europe $e^{14,19}$.

Colistin is the most complicated antibiotic for inhalation intake, because it is a pro-drug (colistimethate), which should be hydrolyzed for its activation. The latter process is too slow and is accompanied by a release of formaldehyde and bisulfites. Colistin is a mixture of cyclic cationic peptides, which can damage not only microbial cells, but also respiratory tract and pulmonary cells ${ }^{1}$.

Patients generally tolerate colistimethate sodium good. The most important side effect is bronchospasm $^{20}$. Wheezing with a temporary decrease of forced expiratory volume $\left(\mathrm{FEV}_{1}\right)$ was registered in $17.7 \%$ of patients ${ }^{15,21}$. Especially often, bronchial spasm is noted in patients with a bronchial asthma or hyperactivity of the respiratory tract ${ }^{1}$. This side effect can be relieved by intake of short-acting agonists of beta-2 adrenergic receptors before treatment ${ }^{15}$.

Colistin is not approved for usage in the United States, because of a patient's death after inhalation of the drug, by development of acute respiratory distress syndrome in a patient with a cystic fibrosis ${ }^{1}$. After mixing colistin with sterile water, it turns into a biologically active form with the formation of active components of colistin A (polymyxin E1) and colistin $\mathrm{B}$ (polymyxin E2). In this case, the polymyxin E1 is toxic to the lung tissue. Mixing of colistin in an aqueous solution and storing it for more than 24 hours lead to an increase in the concentration of polymyxin E1 and an elevated toxicity potential ${ }^{15}$. Despite this, colistin is used in centers of cystic fibrosis in the 
United States for the treatment of chronic infection of $P$. aeruginosa ${ }^{15}$.

\section{Aminoglycoside antibiotics}

Aminoglycosides are among the most effective and safe antibiotics for inhalation intake ${ }^{1}$. These antibacterial drugs have several characteristics, which make them attractive options for the delivery of aerosol. First, their antibacterial effectiveness depends on the concentration, that is, the high concentration of the drug, which is achieved in the lungs after inhalation, can lead to a pronounced bactericidal action and, consequently, improve clinical efficacy ${ }^{7}$. Secondly, they have a dose-dependent systemic toxicity, that is, the highest doses that can be used for intravenous intake result in low permeability into the lungs ${ }^{6,22}$. Finally, aminoglycosides often maintain activity against the Gram-negative microorganisms, which are common pathogens for severe chronic infections of the respiratory tract ${ }^{7}$. For these reasons, the main part of the literature concerning the delivery of antimicrobial substance with an inhalation method is concentrated on aminoglycosides ${ }^{7,23,24}$.

\section{Tobramycin}

The aminoglycoside tobramycin is an antibacterial drug that inhibits the synthesis of protein, irreversibly binding to subunits of 305 bacterial ribosome ${ }^{25}$.

Tobramycin, intended for intravenous intake, before the appearance of the inhalation form, was diluted with a physiological solution and used in inhalations through a nebulizer ${ }^{28}$. A specific formula of tobramycin for inhalation was developed in the $1980 \mathrm{~s}^{15}$. In studies published in the early 90's, the effectiveness of this drug in chronic lung pathology, in particular for the elimination of P. aeruginosa in patients with cystic fibrosis, was established ${ }^{15}$.

This antibacterial agent is effective against most Gram-negative microorganisms, but usually it does not exhibit significant effects against the strains of Burkholderia cepacia complex and S. maltophilia, although it affects the strains of Enterococcus and Staphylococcus ${ }^{25}$. The bactericidal activity against most aerobic Gram-negative microorganisms, including against $\mathrm{P}$. aeruginosa, depends on the concentration of the drug.

During the intravenous intake of tobramycin, its penetration into the lungs is small and constitutes $32 \%$, the concentration in the sputum is less than $10 \%$ of the minimum inhibitory concentration (MIC), and the risk of toxic effects is quite high ${ }^{1}$.

Since the bactericidal effect can be reliable only in concentrations containing 25 -fold minimal inhibitory concentration, for achieving a concentration that inhibits $P$. aeruginosa in the respiratory tract, high doses of the drug are required that can only be achieved with inhalation intake ${ }^{15}$.

Nowadays, inhalational tobramycin (IT) is one of the most common antibacterial drugs used to eliminate blue-purulent infection in patients with cystic fibrosis. This is due to many factors. In particular, it is known that the penetration through the wall of the bacterial cell is an energy-dependent process and it worsens in anaerobic conditions, therefore the low partial pressure of oxygen in purulent cork in cystic fibrosis (CF) can limit the effectiveness of aminoglycosides ${ }^{14}$. In a solution of tobramycin for inhalations, the drug particles are charged positively, and it is believed that with CF tobramycin is bound in the respiratory tracts to negatively charged DNA strands and membranes of $\mathrm{P}$. aeruginosa ${ }^{14}$. The choice of tobramycin for inhaled therapy is due to its high anti-pseudomonadal activity, which exceeds such activity for gentamycin, with a low level of initial resistance of $P$. aeruginosa in patients with CF, a long-term aftereffect (suppression of a bacterial growth in vivo up to 10-12 hours after single usage), a chemical stability in different conditions, a lower toxicity than other aminoglycosides have, and acceptable flavoring properties ${ }^{10}$.

When the inhalational tobramycin is used, the drug mainly stays in the respiratory tract, and it doesn't penetrate through the respiratory epithelium. The bioavailability of tobramycin depends on the inhalation technique and on the state of the respiratory tract ${ }^{1}$. The tobramycin is excreted mainly with sputum, a small part - with a glomerular filtration ${ }^{1,23}$.

Against the background of an increase in frequency of the inhalational tobramycin in patients with CF in the last decade, there has been a progressive increase in the minimum inhibitory concentration (MIC) of this antibiotic for $P$. aeruginosa. The widespread CF causative agents, such as Stenotrophomonas maltophilia and Burkholderia cepacia, become resistant to tobramycin ${ }^{10,18}$.

The use of the inhalational tobramycin in patients with CF is justified from the point of view of the evidence-based medicine (level of evidence $\mathrm{A}$ ) and is recommended by national and international guidelines for treatment of pulmonary infection caused by $P$. aeruginos $a^{14}$. Currently, indications for inhaled intake of tobramycin in patients with bronchiectasis and nosocomial pneumonia are being expanded ${ }^{26}$. High efficiency and safety of theinhalational tobramycin usage in children - chronic carriers of a tracheostomy tube are shown ${ }^{27}$.

Currently, in the world 3 drugs of tobramycin especially designed for inhalations are widely used: tobramycin - a solution for inhalations «Bramitob», 
«Tobi» and tobramycin in the form of powder - «Tobi Podhaler». All these drugs are intended for a basic therapy in adults and children with CF and a confirmed infection with $P$. aeruginosa $a^{28,29}$.

Preparations of tobramycin solutions for inhalations do not differ one from another in composition, way of inhalation and destination scheme ${ }^{14}$. However, the existing differences in the properties of these solutions (concentration, osmolarity) determine their differences in the rate of inhalation (the time of inhalation of "Bramitob“ is 30\% less) and the tolerability of the therapy (in a multicenter, randomized, controlled trial, the number of patients who left because of the cause of undesirable effects from the side of the respiratory system (cough, bronchospasm), was less using „Bramitob“ in comparison with the drug "Tobi") ${ }^{14}$.

The tobramycin in the form of powder (dry powder) for inhalations has been developed and registered in recent years. The particles containing the active substance (Pulmonary Spheres) are packed into capsules and are sprayed with a portable powder inhaler TT326 (Novartis Pharmaceuticals) ${ }^{14}$. Each capsule with the tobramycin contains $28 \mathrm{mg}$ of active substance $^{38}$. Time required to inhale a single dose of the drug is 6 minutes, which is 14 minutes less than for „Tobi“ inhalation ${ }^{30}$.

Unlike to parenteral, inhalational forms of tobramycin do not have nephrotoxicity or ototoxicity ${ }^{28}$. This is due to the fact that the inhalational form provides a low concentration of tobramycin in blood plasma after inhalation $(<1 \mathrm{mg} / \mathrm{L})$, which is much lower than the concentration that causes systemic toxic effect $(>10-12 \mathrm{mg} / \mathrm{L})^{28}$.

The inhaled tobramycin is mainly well tolerated. The most common side effects are cough (41-88\%), voice change (12-16\%), and ear tension $(3 \%)^{15,31}$. The symptoms, as a rule, are transient and stop when the medicinal product is discontinued. However, the complaint of ear tension may be one of the initial symptoms of severe ototoxicity ${ }^{15}$.

The studies show that children between the age of 6 months and 6 years tolerate inhalations withtobramycin solution well without any side effects. The time of the procedure increases according to the age of the patient. Some children (in the age group from 6 months to 3 years), due to the duration of the procedure up to $25-30$ minutes, need breaks during the inhalation for 3-5 minutes ${ }^{32}$.

\section{Amikacin}

Amikacin is a semi-synthetic antibiotic from the group of aminoglycosides, which has a wide range of antibacterial effect. It is the most active against gram-negative microorganisms, including strains resistant to gentamycin. For the aerosol therapy the amikacin is used twice a day $-100 \mathrm{mg}(2 \mathrm{ml})$, diluted in $2.3 \mathrm{ml}$ of a physiological solution ${ }^{33}$.

The inhaled intake of amikacin is a perspective addition to the standard therapy for pulmonary non-tuberculous mycobacterial (NTM) infections. The use of the aerosolized amikacin with a standard oral antibiotic therapy for pulmonary NTM infection can improve the effectiveness of treatment without increasing the risk of systemic toxicity ${ }^{22}$.

It has been established that in comparison with the systematic use of amikacin, the aerosolized form of the drug has a lower amount of toxic side effects ${ }^{34}$. So, according to data of K.N. Olivier et al (2013), only two patients $(10 \%)$ stopped treatment due to hearing loss, and one of them could renew treatment at a lower dose without additional ototoxicity ${ }^{24}$. The dysphonia was a relatively frequent symptom, but it could have been reduced by adjusting the dose practically in all patients. Side effects of the therapy also included sore throat (transient) and oral candidiasis ${ }^{22}$.

Very perspective is usage of the inhalation form of liposomal amikacin. Thus, in an open long-term research, which studied the usage of the "Arikace“ drug during cystic fibrosis at a dose of $560 \mathrm{mg}$ per day by repeated courses of 28 days with intervals of 56 days, its apparent clinical effect was proved in the form of the improved pulmonary function and decreased bacterial insemination, which were stored even in the non-inhalation period ${ }^{14,19}$.

\section{Aztreonam}

Aztreonam is a synthetic antibiotic of the monobactam range (monocyclic $\beta$-lactam) that is active against the Gram-positive aerobic microorganisms, with activity against $\mathrm{P}$. aeruginosa and other Gram-negative pathogens, and resistant to most $\beta$-lactamases ${ }^{14,15}$.

Aztreonam lysine is a new medical form that was certified in 2010 for aerosol treatment of infection caused by $P$. aeruginosa in patients with $\mathrm{CF}^{14}$. In particular, the drug „AZLI“ includes substances that are safe for inhalations, while Aztreonam arginine, which is used for intravenous intake, with a prolonged inhalational therapy, can cause inflammation in the respiratory tract in patients with $\mathrm{CF}^{35}$. Aztreonam lysine is intaken through the eFlow electronic nebulizer, providing deposition in the peripheral regions of the lungs after 2 minutes of inhalation ${ }^{36}$. Clinically significant synergy of the inhaled aztreonam with aminoglycosides against $P$. aeruginosa has been proved ${ }^{14}$.

In a double-blind placebo-controlled research, patients with CF over 12 years of age, in a stable state, independently took "AZLI" once a day with an increased dose from 75 to 150 and $225 \mathrm{mg}$, or 
placebo. The preservation of the anti-syngene activity of the antibiotic when intaken via a nebulizer and the absence of its activity inhibition with sputum was found ${ }^{14}$. The conducted analysis of the usage of aztreonam lysine in 195 patients showed that a prolonged usage of this drug is safe and effective ${ }^{37}$. This research demonstrated improved lung function and quality of life without increasing resistance to aztreonam ${ }^{15}$.

In a 18-month research, the confirmation of safety and efficacy of the drug in pediatric patients has been confirmed ${ }^{37}$. As a rule, the inhaled aztreonam is well tolerated ${ }^{15}$. The most commonly reported side reactions include cough $(32-35 \%)$, headache $(6-11 \%)$, bronchospasm (6-10\%), nasal congestion (7-10\%) and rhinorrhea $(7 \%)^{15,35}$. There are reports about patients with the development of bronchospasm because of the usage of this drug, so, it is necessary to take into account the results of the usage of a controlled trial dose under the supervision of a doctor, especially in patients with severe pulmonary disease ${ }^{15}$.

\section{Fluoroquinolones}

Fluoroquinolones are important antibacterial agents in the treatment of respiratory diseases, taking into account their high efficiency to a relatively wide range of microorganisms, a special mechanism of action and a good permeability into the pulmonary tissue $^{38}$. The usage of this group of drugs in pediatric is limited due to possible side effects, in particular arthro- and chondrotoxicity ${ }^{38,26}$. These drugs are permitted to be used for the eradication of $\mathrm{P}$. aeruginosa in children with cystic fibrosis. That's why, in case of cystic fibrosis and other severe chronic processes in the lungs caused by Pseudomonas aeruginosa, the usage of the inhaled forms of fluoroquinolones in children is very promising, taking into account the lower number of side effects and the possibility of using higher concentrations of the drug at the center of the lesion ${ }^{15,16}$.

\section{Ciprofloxacin}

Ciprofloxacin is fluoroquinolone, which inhibits the synthesis of bacterial DNA, blocking DNA-gyrase and topoisomerase IV, which are required for DNA replication ${ }^{38}$. The drug is widely used in oral form in patients with $\mathrm{CF}$ and other diseases.

Ciprofloxacin is used for inhalations in the form of dry powder ${ }^{39}$ and a liposomal form ${ }^{15,40}$. Taking into account its adequate tolerability and a minimal systemic action, this drug is used to treat patients with chronic inflammatory diseases of the lungs caused by P. aeruginosa $a^{15}$.

The liposomal form of the inhaled ciprofloxacin has potential benefits, including controlled and long-term effect release of the drug at the site of action, protection against drug degradation, systemic exposure and cellular uptake ${ }^{15,41}$.

The intake of cyprofloxacin in the form of an aerosol (early known as BAY Q3939), with small particles or enclosed in liposomes to the guinea pigs infected with Legionella pneumophilia, or mice infected with Francisella tularensis, prevented the death of animals, that indicates the delivery of aerosol into the lower respiratory tract ${ }^{14}$. After the successful completions of Phase I and II of the studies on safety and efficacy of the inhaled liposomal ciprofloxacin, the possibility of the drug intake once a day was confirmed ${ }^{14,19}$. The most common side effects reported while using the inhaled ciprofloxacin in powder form are bitter taste in the mouth (14-94\%), bronchospasm (50-67\%), headache (17-33\%) and cough (3-17\%) $)^{15,39,42}$.

\section{Levofloxacin}

The inhaled levofloxacin has been recently introduced and is currently approved to be used in Europe in patients with CF and chronic P. aeruginosa infection ${ }^{15}$. The medical form of levofloxacin for aerosol intake was registered under the name "Aeroquin“ and specially prepared for intake via a nebulizer eFlow $^{14}$. Duration of inhalation of the drug does not exceed 4-6 minutes ${ }^{19}$. The main way of eliminating the drug from the lungs is systemic absorption ${ }^{14}$.

The conducted researches that compared different doses of the inhaled levofloxacin $(120,240 \mathrm{mg}$ a day, $240 \mathrm{mg}$ twice a day) with placebo in 151 patients demonstrated a dose-dependent improvement in lung function and a significant reduction exacerbations frequency within 28 days $^{15}$. The most commonly reported side effects during the levofloxacin usage include cough, taste disturbance, general weakness ${ }^{43,44}$.

\section{Fosfomicin}

Fosfomicinis a bactericidal, antibacterial agent of a wide spectrum of activity that is capable of inhibiting the initial stage of the peptidoglycan formation of the cell wall of bacteria. The drug also has anti-adhesive properties that prevent bacteria sticking to the epithelium (in particular, the urogenital tract).

The inhaled fosfomicin has an antimicrobial activity against both gram-negative and gram-positive microorganisms. The remedy is recommended to be combined with other antibiotics to avoid the rapid development of resistance to it ${ }^{14,27}$. A combination of fosfomicin and tobramycin in a ratio of 4: 1 was especially developed by Gilead Sciences (USA) for usagevia the eFlow nebulizer to control P. aeruginosa $a^{14,19}$. However, there is a high chance for some patients to experience side effects such as local reactions, irritation of the respiratory tract mucous membrane, voice 
obstruction, bronchial obstruction, bronchial hyperresponsiveness ${ }^{14}$.

In recent years, cephalosporins, in particular ceftazidime, are more often used for inhalations ${ }^{45}$. The drug is used most for the treatment of ventilatory-associated pneumonia and cystic fibrosis (in the presence of infection with Burkholderia cepacia). An injectable solution of ceftazidime is used, diluted with a physiological solution and injected into the respiratory tract using a jet spray ${ }^{46}$. Nevertheless, the usage of the inhaled beta-lactam antibiotics is not entirely appropriate, since their antibacterial activity depends on the time of action that requires frequent inhalations. For example, for effective inhalation therapy with ceftazidime, inhalations are required every 3 hours ( 8 times a day), which is difficult to implement in practice ${ }^{1}$.

\section{General side effects and disadvantages of the inhaled antibiotics usage.}

According to Quon B.S. et al (2014), known or potential adverse effects of the inhaled antibiotics are divided into three main categories: local, systemic, and emergence of antibiotic-resistant organisms ${ }^{46}$.

Local effects include transient bronchial obstruction due to high osmolality and the presence of conservants in some solutions ${ }^{11}$. Modified taste, dysphonia and throat irritation are also common side effects associated with the inhaled antibiotics. To avoid the development of these side effects, only special inhalational forms should be used and pre-inhalation of the bronchodilator should be made. The osmolality of the solution for inhalations should be $150-1200 \mathrm{mOsm} / \mathrm{kg}$, sodium content $77-154 \mathrm{mEq} / \mathrm{L}$, neutral $\mathrm{pH}$, the content of chlorides should be at least $30 \mathrm{mEq}$ for better penetration of the antibiotic into the cells and in order to avoid the development of cough and bronchospasm ${ }^{1}$.

Modern knowledge about the systemic effects of the inhaled antibiotics remains limited, especially for forms of antibiotics specifically designed for usage in the respiratory tract ${ }^{46}$. Usually systemic side effects are special for different groups of antibiotics and have been discussed above; however, it is worth noting some circumstances that increase systemic toxic effects of drugs. In particular, the systemic effect increases with abnormality of kidney and liver function, which reduces the efficiency of the antibiotic utilizing that has fallen into the blood stream. The development of systemic side effects may be associated with the absorption of antibiotics into the blood, which is significantly increased in pneumonia compared with healthy lungs ${ }^{1,47,48}$.

The most common clinical problem with the use of the inhaled antibiotics is the emergence of resistant pathogens. This is especially actual for long-term aeration of $P$. aeruginosa, Burkholderia cepacia,
Stenotrophomonas maltophilia and Achromobacter xylosoxidans in patients with cystic fibrosis ${ }^{46}$.

Also, the disadvantages of the infusion antibiotic therapy associated with the drugs intake via the nebulizer are important:

1) Duration of the procedure. For patients, who use inhaled antibiotics, nebulizer therapy can take up to 2 hours a day. This time is required to prepare a nebulizer, inhale the drug and clean the nebulizer after its usage. For colistin and other drugs, it is necessary up to 10 minutes to dilute the appropriate dose in water for injections in order to produce the isotonic solution ${ }^{6,49}$.

2) The usage of nebulizers includes a risk of infection if the device is not properly cleaned ${ }^{50}$.

3) Nebulizers are cumbersome and less portable than other devices ${ }^{6}$.

4) Nebulizers require regular maintenance and replacement of components ${ }^{6}$.

In addition, the cost of the inhaled antibacterial drugs is not less important for patients as compared to the systemic drugs and the cost of a nebulizer with its components.

\section{Conclusions}

The usage of the inhaled antibiotics in children is a promising direction of the respiratory diseases treatment, taking into account the ability to use locally high concentrations of the drug with minimal systemic complications. These drugs have the most proven efficacy when treating chronic infections with Pseudomonas aeruginosa and other pathogens in patients with cystic fibrosis, where their usage is considered the most appropriate today. The inhaled antibiotics are practically not used as a monotherapy, but only in combination with systemic antibiotics. They cannot be an alternative or a substitute for systemic drugs. However, in severe pulmonary diseases, where the effectiveness of the traditional antibiotic therapy has bad results, the inhaled antibiotics are means of choice. That's why the development of new inhalational forms of antibacterial drugs, the improvement of already existing dosage forms and ways of drugs intake into the respiratory tract is a perspective direction of modern pediatric pulmonology and medicine in general.

\section{Compliance with Ethics Requirements:}

„The authors declare no conflict of interest regarding this article"

„The authors declare that all the procedures and experiments of this study respect the ethical standards in the Helsinki Declaration of 1975, as revised in 2008(5), as well as the national law." 


\section{References}

1. Kuzovlev AN, Moroz VV, Golubev AM.Inhaled antibiotics in treatment of nosocomial pneumonia. Anesteziologiya $i$ reanimatologiya. 2015; 60 (4): 55-61[in Russian].

2. Izquierdo M, Gomez-Alamillo C, Ortiz F. Acute renal failure associated with use of inhaled tobramycin for treatment of chronic airway colonization with Pseudomonas aeruginosa. Clin. Nephrol. 2006; 66: 464-7.

3. Holloway KA. Promoting the rational use of antibiotics Regional Health Forum - Volume 15, Number 1, 2011. 122-130.

4. Redko OK, Zahorodnii MP, Ponor OB. Antimicrobial resistance and the benefits of protected cephalosporins III generation in the treatment of children. Khvoroby ta antybiotyky. 2011;2(05). Available from: http://www.mif-ua.com/ archive/article/24851[in Ukrainian].

5. Sievert D. Ricks P, Edwards J. Antimicrobial-resistant pathogens associated with healthcare-associated infections: summary of data reported to the National Healthcare Safety Network at the Centers for Disease Control and Prevention, 2009-2010. Infect Control Hosp. Epidemiol. 2013; 34 (1): 1-14.

6. Tiddens HAWM, Bos AC, Mouton JW. Inhaled antibiotics: dry or wet? Eur Respir J. 2014; 44: 1308-1318.

7. Wenzler E, Fraidenburg DR, Scardina T, Danziger LH. Inhaled antibiotics for Gram-negative respiratory infections Clin Microbiol Rev. 2016;29(3): 581-632.

8. Polovnikov SG, Kuzovlev AN, Ilyichev AN. An experience of administration of inhaled tobramycin in severe nosocomial pneumonia. Russian Pulmonology. 2011;(2):109-112[in Russian].

9. Ioannidou E, Siempos I, Falagas M Administration of antimicrobials via the respiratory tract for the treatment of patients with nosocomial pneumonia: a meta-analysis. J Antimicrob Chemother. 2007; 60 (6): 1216-26.

10. Chikina S.Yu. New inhalation form of tobramycin for chronic Pseudomonas aeruginosa infection in patients with cystic fibrosis. Lechebnoe delo. 2011; 4:105-112 [in Russian].

11. Pai VB, Nahata MC. Efficacy and safety of aerosolized tobramycin in cystic fibrosis.Pediatr Pulmonol. 2001;32:314327.

12. Palmer LB. Aerosolized antibiotics in the intensive care unit. Clin Chest Med. 2011; 32 (3): 559-74.

13. Krasovskiy SA, Amelina EL, Kondrat'eva EI, Voronkova AYetal. Drug treatment of cystic fibrosis patients in russian federation according to the national register, 2014. Russian Pulmonology. 2016;26(5):539-555[in Russian].

14. Kashirskaya NYu, Kapranov NI. Place inhalation forms of antibacterial literature preparations in the therapy of bacterial infection of the lung in patients with cystic fibrosis. Pulmonology and allergology. 2012; 3:5-12 [in Russian].

15. Maselli DJ, Keyt H, Restrepo MI, Blasi FB. Inhaled antibiotic therapy in chronic respiratory diseases Int J Mol Sci. 2017; 18(5): 1062

16. Mogayzel PJ Jr, Naureckas ET, Robinson KA, et al. Cystic Fibrosis Foundation pulmonary guideline. Pharmacologic approaches to prevention and eradication of initial Pseudomonas aeruginosa infection. Ann Am Thorac Soc. 2014;11:1640-1650.

17. Ehrmann S, Roche-Campo F, Sferrazza Papa GF, Isabey D, Brochard L, Apiou-Sbirlea G, REVA Research Network. Aerosol therapy during mechanical ventilation: an international survey.Intensive Care Med.2013; 39 (6): 1048-56

18. Parkins MD, Elborn JS. Tobramycin inhalation powder: a novel drug delivery system for treating chronic Pseudomonas aeruginosa infection in cystic fibrosis. Expert Rev Respir. Med.2011; 5(5):609-622.

19. Ballmann M, Smyth A, Geller DE. Therapeutic approaches to chronic cystic fibrosis respiratory infections with available, emerging aerosolized antibiotics. Respir Med.2011;105(Suppl 2):S2-S8.

20. Le J, Ashley ED, Neuhauser MM, et al. Consensus summary of aerosolized antimicrobial agents: application of guideline criteria. Insights from the Society of Infectious Diseases Pharmacists. Pharmacotherapy. 2010; 30 (6): 562-84.

21. Hodson ME, Gallagher CG, Govan JR. A randomised clinical trial of nebulised tobramycin or colistin in cystic fibrosis. Eur Resp J 2002, 20, 658-664.

22. Davis KK, Kao PN, Jacobs SS, Ruoss SJ. Aerosolized amikacin for treatment of pulmonary Mycobacterium avium infections: an observational case series. BMC Pulmonary Medicine.2007;7:2.

23. Geller DE, Pitlick WH, Nardella PA et al. Pharmacokinetics and bioavailability of aerosolized tobramycin in cystic fibrosis. Chest 2002; 122: 219-226.

24. Olivier KN, Shaw PA, Glaser TS, et al. Inhaled amikacin for treatment of refractory pulmonary nontuberculous mycobacterial disease. Ann Am Thorac Soc. 2014;11(1):30-5.

25. Kapranov NI. Pharmacotherapy of cystic fibrosis: inhaled antibiotics. Meditsinskiy sovet. 2013;11:62-69 [in Russian].

26. Principi N, Esposito S. Appropriate use of fluoroquinolones in children. International Journal of Antimicrobial Agents. 2015.6.1-6.

27. Petrova SI, Panyutina YaV, Peshekhonova YuV, Tsvetkov EA, Galustyan AN, Kondrashova EM. Use of inhaled tobramycin in children with chronic airways diseases and Pseudomonas aeruginosa infection carriage. Vestnik anesteziologii i reanimatologii. 2012;9(2):064-068 [in Russian].

28. Amelina EL, Krasovsky SA. Tobramycin inhalations in therapy of chronic infection Pseudomonas aeruginosa in cystic fibrosis. Russian Pulmonology. 2013;(4):109-114[in Russian].

29. Chuchalin A, Csiszér E, Gyurkovics K, et al. A formulation of aerosolized tobramycin (Bramitob) in the treatment of patients with cystic fibrosis and Pseudomonas aeruginosa infection: a double-blind, placebo-controlled, multicenter study. Paediatr. Drugs. 2007;9(1): 21-31.

30. Geller DE, Weers J, Heuerding S. Development of an inhaled dry powder formulation of tobramycin using PulmoSphere technology. J Aerosol Med Pulm Drug Deliv. 2011; 24 (4): 175-182.

31. Murphy TD, Anbar RD, Lester LA, et al. Treatment with tobramycin solution for inhalation reduces hospitalizations in young CF subjects with mild lung disease. Pediatr Pulmonol.2004;38:314-320.

32. Simonova O, Chistyakova V, Lazareva A, Katosova L. Inhalation antibiotics are essential for the control of infection in children with cystic fibrosis. Current pediatrics. 2011;10(3):119-123[in Russian].

33. Sukhan VS. Nebulizer therapy in clinical practice: methodological recommendations. Uzhhorod, 2010 [in Ukrainian].

34. Peloquin CA, Berning SE, Nitta AT, et al. Aminoglycoside toxicity: daily versus thrice-weekly dosing for treatment of mycobacterial diseases. Clin Infect Dis 2004;38:1538-1544.

35. McCoy KS, Quittner AL, Oermann CM, Gibson RL, Retsch-Bogart GZ, Montomery AB. Inhaled aztreonam lysine for chronic airway Pseudomonas aeruginosa in cystic fibrosis. Am J Respir Crit Care Med. 2008;178:921-928.

36. Keller $\mathrm{M}$ et al. High efficiency pulmonary drug delivery of a novel formulation of aztreonam by the eFlow ${ }^{\mathrm{TM}}$. Poster 
$030 / /$ Congress of the International Society for Aerosols in Medicine. Baltimore, 2003.

37. Oermann CM, Retsch-Bogart GZ, Quittner AL, et al. An 18-month study of the safety and efficacy of repeated courses of inhaled aztreonam lysine in cystic fibrosis. Pediatr Pulmonol. 2010;45:1121-1134.

38. Choi S-H, Kim EY, Kim Y-J. Systemic use of fluoroquinolone in children. Korean J Pediatr. 2013; 56(5): 196-201.

39. Stass H, Nagelschmitz J, Willmann S, Delesen H, Gupta A, Baumann S. Inhalation of a dry powder ciprofloxacin formulation in healthy subjects: A phase I study. Clin Drug Investig.2013;33:419-427.

40. Bruinenberg P, Blanchard JD, Cipolla DC, Dayton F, Mudumba S, Gonda I. Inhaled liposomal ciprofloxacin: once a day management of respiratory infections. Respir Drug Deliv.2010;1:73-81.

41. Haworth C, Wanner A, Foehlich J, et al. Inhaled liposomal ciprofloxacin in patients with bronchiectasis and chronic pseudomonas aeruginosa infection: Results from two paral lel phase III trials (ORBIT-3 and -4). Am J Respir Crit Care Med. 2017

42. Dorkin HL, Staab D, Operschall E, Alder J, Criollo M. Ciprofloxacin DPI: A randomised, placebo-controlled, phase IIb efficacy and safety study on cystic fibrosis. BMJ Open Respir. Res. 2015;2:e000100.

43. Flume PA, VanDevanter DR, Morgan EE, et al. A phase 3, multi-center, multinational, randomized, double-blind, placebo-controlled study to evaluate the efficacy and safety of levofloxacin inhalation solution (APT-1026) in stable cystic fibrosis patients. J Cyst Fibros. 2016;15:495-502.

44. Geller DE, Flume PA, Staab D, Fischer R, Loutit JS, Conrad DJ. Levofloxacin inhalation solution (MP-376) in patients with cystic fibrosis with Pseudomonas aeruginosa. Am J Respir. Crit Care Med. 2011;183:1510-1516.

45. Lu Q, Yang J, Liu Z, et al. Nebulized ceftazidime and amikacin in ventilator associated pneumonia caused by Pseudomonas aeruginosa. Am J Respir Crit Care Med. 2011;184(1):106-115.

46. Quon BS, Goss CH, Ramsey BW. Inhaled antibiotics for lower airway infections. Ann Am Thorac Soc. 2014; 11(3); 425-434.

47. Izquierdo M, Gomez-Alamillo C, Ortiz F. Acute renal failure associated with use of inhaled tobramycin for treatment of chronic airway colonization with Pseudomonas aeruginosa. Clin Nephrol. 2006; 66: 464-7.

48. Patatanian L. Inhaled tobramycin-associated hearing loss in an adolescent with renal failure. Pediatr Infect Dis J. 2006; 25 (3): 276-8.

49. Sawicki GS, Tiddens H. Managing treatment complexity in cystic fibrosis: challenges and opportunities. Pediatr Pulmonol 2012; 47: 523-533.

50. Blau H, Mussaffi H, Mei Zahav M, et al. Microbial contamination of nebulizers in the home treatment of cystic fibrosis. Child Care Health Dev 2007; 33: 491-5. 